\title{
Technological functionality of inulin and oligofructose
}

\author{
A. Franck* \\ ORAFTI Active Food Ingredients, Research \& Development, Aandorenstraat 1, 3300 Tienen, Belgium
}

\begin{abstract}
Inulin and oligofructose are functional food ingredients which offer a unique combination of nutritional properties and important technological benefits. They are found in many vegetables and fruits and can be industrially obtained from chicory roots. In food formulations, inulin and oligofructose may significantly improve organoleptic characteristics. Their incorporation allows upgrading of both taste and mouthfeel in a wide range of food applications. Oligofructose is highly soluble and possesses technological properties that are closely related to those of sugar and glucose syrups. It is often used in combination with high intensity sweeteners. Inulin has a much lower solubility, improves the stability of foams and emulsions and shows exceptional fat-like characteristics when used under the form of a gel in water. Fat and carbohydrate replacement with chicory inulin and oligofructose offers the advantage of not compromising on taste and texture, while delivering nutritionally enhanced products.
\end{abstract}

Inulin: Oligofructose: Applications: Properties

\section{Introduction}

As more and more scientific data become available, the nutritional benefits of inulin and oligofructose become further apparent (Roberfroid, 1997; Roberfroid \& Delzenne, 1998). These ingredients offer a unique combination of nutritional and technological advantages. Therefore they are often taken as practical illustrations of active food ingredients for 'functional foods' (Van Loo et al. 1999).

Inulin and oligofructose are widely found in nature, in a variety of plants and in some bacteria and fungi. Plants containing them include leeks, onions, garlic, asparagus, Jerusalem artichokes, dahlias, yacon and chicory (Van Loo et al. 1995). Inulin and oligofructose have thus always been part of the normal human diet (Van Loo et al. 1995; Moshfegh et al. 1999).

They are legally classified as food or food ingredients (not as additives) in all EU countries. The Authorities in Australia, Canada and Japan came to the same conclusions. In the USA a panel of recognised experts has confirmed the GRAS (Generally Recognized As Safe) status of chicory inulin and oligofructose. In all these countries, they can be used without specific limitations as ingredients in foods and drinks. Most countries also have agreed that inulin and oligofructose may be labelled as dietary fibres (Coussement, 1999; Prosky, 1999).

\section{Industrial production}

During the early 1990 s, several attempts were made to isolate and purify inulin and oligofructose for use as dietary supplements. Nowadays, they are used in a pure form as ingredients in many food products.

Given their high inulin content $(>15 \%)$, Jerusalem artichokes, dahlias and chicory were initially considered for industrial production in temperate regions, but for several reasons chicory (Cichorium intybus) is nearly exclusively processed (De Leenheer, 1996). The roots of chicory, which are also used in different countries for the production of a coffee substitute (after roasting), look like small oblong-shaped sugar beets. Their inulin content is high (more than $70 \%$ on dry substance) and fairly constant from year to year.

The production process, which is represented in Fig. 1, involves the extraction of the naturally occurring inulin from chicory roots, in a manner very similar to the extraction of sucrose from sugar beets (diffusion in hot water), followed by refining using technologies from the sugar and starch industries (e.g. ion exchangers), and then evaporation and spray-drying.

Oligofructose is produced using two different manufacturing techniques that deliver slightly different end products. Chicory oligofructose is obtained by partial enzymatic hydrolysis of inulin (using an endo-inulinase), eventually followed by spray-drying (Fig. 1), but it can also be synthesised from sucrose using fructosyl-transferase (Bornet, 1994; De Leenheer, 1996).

\section{Technological properties}

Chicory inulin is available as a white, odourless powder

Note: For the definition of the terms inulin and oligofructose please refer to the introductory paper (p. S139) and its footnote.

*Corresponding author: Dr A. Franck, tel +32 16801218, fax +32 16801359, email anne.franck@orafti.com 


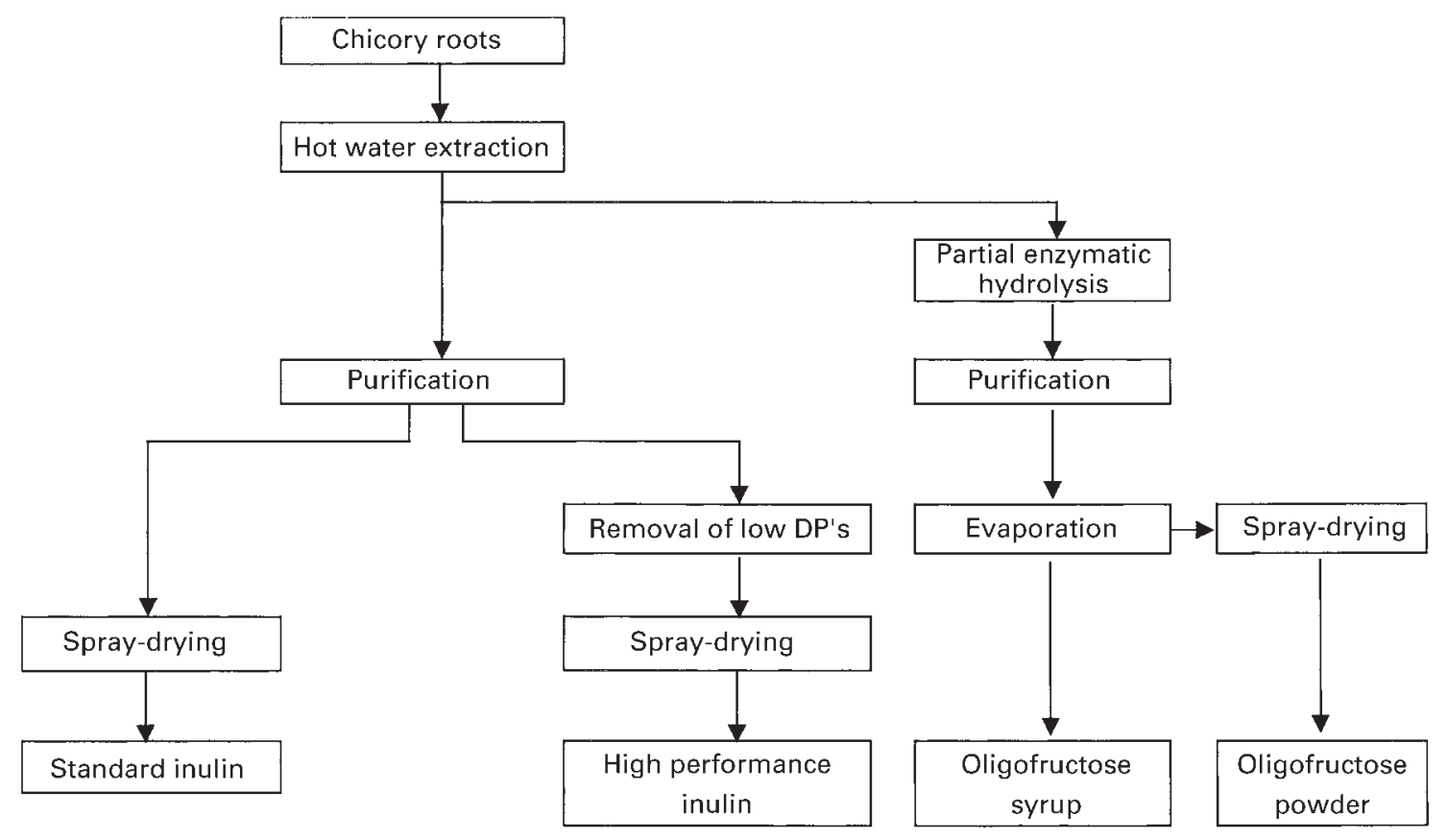

$\mathrm{DP}=$ degree of polymerisation

Fig. 1. Industrial production process of chicory inulin and oligofructose.

and oligofructose as powder and colourless viscous syrup (75\% dry substance), all with a high purity and a wellknown chemical composition. Their physico-chemical properties are summarised in Table 1.

Inulin has a bland neutral taste, without any off-flavour or aftertaste. Standard inulin is slightly sweet (10\% sweetness in comparison with sugar), whereas high performance inulin (from which the fraction with a degree of polymerisation lower than ten has been removed) is not. It combines easily with other ingredients without modifying delicate flavours. It is moderately soluble in water (maximum $10 \%$ at room temperature) and brings a rather low viscosity (less than $2 \mathrm{mPa} . \mathrm{s}$ for a $5 \% \mathrm{w} / \mathrm{w}$ solution in water). On the other hand, inulin has a remarkable capacity to replace fat. When thoroughly mixed with water or another aqueous liquid, it forms a particle gel network resulting in a white creamy structure with a short spreadable texture, which can easily be incorporated into foods to replace fat by up to $100 \%$ (Franck, 1993). Such a gel is composed of a tri-dimensional network of insoluble sub-micron crystalline inulin particles in water. Large amounts of water are immobilised in this network, which assures its physical stability. As far as fat replacement is concerned, high performance inulin (patent protected) shows about twice the functionality of standard chicory inulin. Special instant qualities that do not require shearing to give stable homogeneous gels also have been developed using a specific spray-drying process. Inulin works in

Table 1. Physico-chemical characteristics of chicory inulin and oligofructose

\begin{tabular}{|c|c|c|c|}
\hline & Standard inulin & High performance inulin & Oligofructose powder \\
\hline Chemical structure & GFn $(2 \leq \mathrm{n} \leq 60)$ & GFn $(10 \leq n \leq 60)$ & $\mathrm{GFn}+\mathrm{Fn}(2 \leq \mathrm{n} \leq 7)$ \\
\hline Average degree of polymerisation & 12 & 25 & 4 \\
\hline Dry matter (\%) & 95 & 95 & 95 \\
\hline Inulin/oligofructose content (\% on d.m.) & 92 & 99.5 & 95 \\
\hline Sugars content (\% on d.m.) & 8 & $S 0.5$ & 5 \\
\hline $\mathrm{PH}(10 \% \mathrm{w} / \mathrm{w})$ & $5-7$ & $5-7$ & $5-7$ \\
\hline Sulphated ash (\% on d.m.) & $<0.2$ & $<0.2$ & $<0.2$ \\
\hline Heavy metals (ppm on d.m.) & $<0.2$ & $<0.2$ & $<0.2$ \\
\hline Appearance & White powder & White powder & White powder \\
\hline Taste & Neutral & Neutral & Moderately sweet \\
\hline Sweetness $(v$. sucrose $=100 \%)$ & $10 \%$ & None & $35 \%$ \\
\hline Solubility in water at $25^{\circ} \mathrm{C}(\mathrm{g} / \mathrm{l})$ & 120 & 25 & $>750$ \\
\hline Viscosity in water $(5 \%)$ at $10^{\circ} \mathrm{C}(\mathrm{mPa} . \mathrm{s})$ & 1.6 & 2.4 & $<1.0$ \\
\hline Functionality in foods & Fat replacer & Fat replacer & Sugar replacer \\
\hline Synergism & Synergy with gelling agents & Synergy with gelling agents & Synergy with intense sweeteners \\
\hline
\end{tabular}

$\mathrm{G}=$ glucosyl unit; $\mathrm{F}$ = fructosyl unit; $\mathrm{d} . \mathrm{m}$. = dry matter. 
synergy with most gelling agents, e.g. gelatine, alginate, kand i-carrageenans, gellan gum and maltodextrins. It also improves the stability of foams and emulsions, such as aerated desserts, ice creams, table spreads and sauces. Inulin can therefore replace other stabilisers in different food products (Franck \& Coussement, 1997).

Oligofructose is much more soluble than inulin (about $80 \%$ in water at room temperature). In the pure form it has a sweetness of about $35 \%$ in comparison with sucrose. Its sweetening profile closely approaches that of sugar, the taste is very clean without any lingering effect and it also enhances fruit flavours. In combination with intense sweeteners such as aspartame and acesulfame $\mathrm{K}$, it provides interesting mixtures offering a rounder mouthfeel and a better sustained flavour with reduced aftertaste, as well as improved stability. Combinations of acesulfame K-aspartame blends with oligofructose also exhibit a significant quantitative synergy (Wiedmann \& Jager, 1997). Oligofructose shows good stability during the usual food processes (e.g. during heat treatments) even if the $\beta$-bonds between the fructose units can be (partially) hydrolysed in very acidic conditions. Fructose is formed in this process which is more pronounced under low $\mathrm{pH}$, high temperature and low dry substance conditions. Oligofructose also contributes towards improved mouthfeel, shows humectant properties, reduces water activity ensuring high microbiological stability, and affects boiling and freezing points. So, in fact, it possesses technological properties that are closely related to those of sugar and glucose syrup (Crittenden \& Playne, 1996).

\section{Food applications}

Inulin and oligofructose can be used for either their nutritional advantages or technological properties, but they are often applied to offer a dual benefit: an improved

Table 2. Overview of food applications with inulin and oligofructose

\begin{tabular}{|c|c|c|c|}
\hline Application & Functionality & Dosage level inulin (\% w/w) & Dosage level oligofructose (\% w/w) \\
\hline Dairy products & $\begin{array}{l}\text { Sugar and fat replacement } \\
\text { Synergy with sweeteners } \\
\text { Body and mouthfeel } \\
\text { Foam stability } \\
\text { Fibre and prebiotic }\end{array}$ & $2-10$ & $2-10$ \\
\hline Frozen desserts & $\begin{array}{l}\text { Sugar and fat replacement } \\
\text { Texture and melting } \\
\text { Synergy with sweeteners } \\
\text { Fibre and prebiotic }\end{array}$ & $2-10$ & $5-12$ \\
\hline Table spreads & $\begin{array}{l}\text { Fat replacement } \\
\text { Texture and spreadability } \\
\text { Emulsion stability } \\
\text { Fibre and prebiotic }\end{array}$ & $2-10$ & - \\
\hline Baked goods and breads & $\begin{array}{l}\text { Fibre and prebiotic } \\
\text { Moisture retention } \\
\text { Sugar replacement }\end{array}$ & $2-15$ & $2-25$ \\
\hline Breakfast cereals & $\begin{array}{l}\text { Fibre and prebiotic } \\
\text { Crispness and expansion }\end{array}$ & $2-25$ & $2-15$ \\
\hline Fillings & $\begin{array}{l}\text { Sugar and fat replacement } \\
\text { Texture improvement }\end{array}$ & $2-30$ & $2-50$ \\
\hline Fruit preparations & $\begin{array}{l}\text { Sugar replacement } \\
\text { Synergy with sweeteners } \\
\text { Body and mouthfeel } \\
\text { Fibre and prebiotic }\end{array}$ & $2-10$ & $5-50$ \\
\hline Salad-dressings & $\begin{array}{l}\text { Fat replacement } \\
\text { Body and mouthfeel }\end{array}$ & $2-10$ & - \\
\hline Meat products & $\begin{array}{l}\text { Fat replacement } \\
\text { Texture and stability } \\
\text { Fibre }\end{array}$ & $2-10$ & - \\
\hline Dietetic products and meal replacers & $\begin{array}{l}\text { Sugar and fat replacement } \\
\text { Synergy with sweeteners } \\
\text { Low caloric value } \\
\text { Body and mouthfeel } \\
\text { Fibre and prebiotic }\end{array}$ & $2-15$ & $2-20$ \\
\hline Chocolate & $\begin{array}{l}\text { Sugar replacement } \\
\text { Fibre } \\
\text { Heat resistance }\end{array}$ & $5-30$ & - \\
\hline Tablets & $\begin{array}{l}\text { Sugar replacement } \\
\text { Fibre and prebiotic }\end{array}$ & $5-100$ & $2-10$ \\
\hline
\end{tabular}




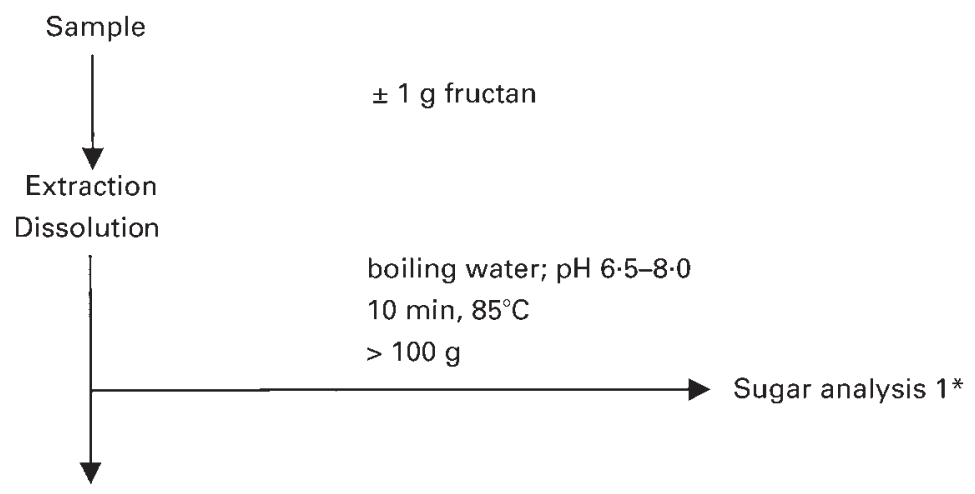

Hydrolysis by amyloglucosidase

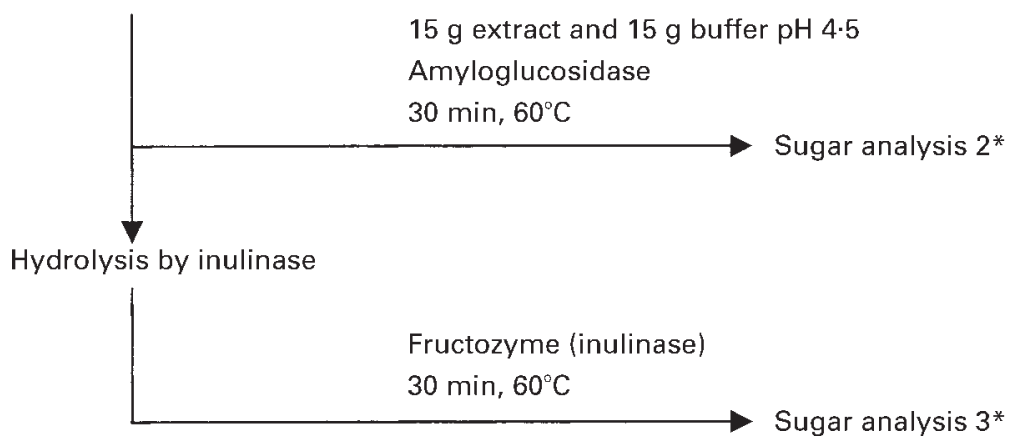

* by ion exchange chromatography

After Hoebregs (1997)

Fig. 2. Analytical method for inulin and oligofructose in food samples.

organoleptic quality and a better-balanced nutritional composition. Table 2 gives an overview of their applications in foods and drinks.

The use of inulin or oligofructose as a fibre ingredient often leads to an improved taste and texture (Franck \& Coussement, 1997). When used in bakery products and breakfast cereals, this presents a major progress in comparison with classical dietary fibres. Inulin and oligofructose give more crispness and expansion to extruded snacks and cereals, and they also increase shelf life. They also keep breads and cakes moist and fresh for longer. Their solubility allows fibre incorporation in watery systems such as drinks, dairy products and table spreads. Inulin is also often used as a dietary fibre in tablets. On the other hand, inulin and oligofructose are more and more applied in functional foods, especially in a whole range of dairy products but also in other foods such as breads, as prebiotic ingredients which stimulate the growth of beneficial intestinal bacteria (Coussement, 1996; Walter, 1999).

Because of gelling characteristics, inulin allows the development of low-fat foods without compromising on taste or texture. This is particularly true in products such as table spreads, butter-like products, dairy spreads, cream cheeses and processed cheeses. It allows the replacement of significant amounts of fat and the stabilisation of the emulsion, while providing a short spreadable texture. Excellent results are obtained in water-in-oil spreads with a fat content ranging from 20 to $60 \%$, as well as in water-continuous formulations containing $15 \%$ fat or less. In low-fat dairy products such as milk drinks, fresh cheeses, yoghurts, creams, dips and dairy desserts, the addition of a small amount of inulin imparts a betterbalanced round flavour and a creamier mouthfeel.

In dairy mousses (chocolate, fruit, yoghurt or fresh cheese-based), the incorporation of inulin improves the processability and upgrades the quality. The resulting products retain their typical structure for a longer time. In frozen desserts, it provides an easy processing, a real fatty mouthfeel, excellent melting properties, as well as freeze-thaw stability. Fat replacement can also be applied in meal replacers, meat products, sauces and soups. For instance, fat-reduced meat products with a creamier and juicier mouthfeel and an improved stability due to water immobilisation can be obtained. Inulin also has found application as a low calorie bulk ingredient and as a fibre in chocolate (e.g. without added sugar), often in combination with a polyol or with fructose.

In the dairy market, dietary products are showing the strongest growth, in particular diet yoghurts with fruit. The incorporation of oligofructose $(1-3 \%)$ in the recipe, often through the fruit preparation, improves mouthfeel, reduces syneresis and offers a synergistic taste effect in combination with aspartame and acesulfame $\mathrm{K}$, without significantly increasing the caloric content. Oligofructose is also often formulated in other (low-calorie) dairy products, frozen desserts and meal replacers (Franck, 1999). 
Its incorporation into baked goods allows the replacement of sugar, fibre enrichment and better moisture retention properties. It also offers good binding characteristics in cereal bars. Its use is straightforward and requires only minor adaptation of the production process, if any. Therefore, oligofructose is an ideal ingredient for bulk properties with lower calories and to provide nutritional benefits without compromising taste or mouthfeel.

\section{Analytical methodologies}

Presently, appropriate legal authorities in most countries have confirmed that inulin and oligofructose can be labelled as 'dietary fibre' for food labelling. However, the classical methods for analysis of dietary fibre (AOAC and Englyst methods) do not analyse them (because they are either too soluble in ethanol or degraded in the acid hydrolysis steps). Recently, based on the results of a collaborative ring test, AOAC International has adopted, as method number 997.08, the 'Fructan method' that allows specifically the accurate quantitative determination of inulin and oligofructose in foods (Hoebregs, 1997). The method, which is shown in Fig. 2, involves treatment of the sample with amyloglucosidase and inulinase enzymes, followed by determination of the released sugars by ion exchange chromatography. This method can be combined with the standard AOAC 'Total Dietary Fibre' method to produce the total amount of fibre to be used for food labelling.

\section{References}

Bornet FRJ (1994) Undigestible sugars in food products. American Journal of Clinical Nutrition 59, 763S-769S.

Coussement P (1996) Pre- and synbiotics with inulin and oligofructose. Food Technology Europe, January, 102-104.

Coussement PAA (1999) Inulin and Oligofructose: Safe Intakes and Legal Status. Journal of Nutrition 129, 7S, 1412S-1417S.

Crittenden RG \& Playne MJ (1996) Production, properties and applications of food- grade oligosaccharides. Trends in Food Science and Technology 7, 353-361.

De Leenheer L (1996) Production and use of insulin: Industrial reality with a Promising future. In Carbohydrates as Organic Raw Materials III, pp. 67-92 [H Van Bekkum, H Röper and AGJ Voragen, editors]. New York, NY: VCH Publishers Inc.

Franck A (1993) Rafticreming: The new process allowing to turn fat into dietary fiber. FIE Conference Proceedings 1992, pp. 193-197. Maarssen: Expoconsult Publishers.

Franck A (1999) Prebiotic sweeteners blends. Food Marketing and Technology 13, 22-24.

Franck A \& Coussement P (1997) Multi-functional inulin. Food Ingredients and Analysis International, October, 8-10.

Hoebregs H (1997) Fructans in foods and food products, ionexchange chromatographic method: Collaborative study. Journal of AOAC International 80, 1029-1037.

Moshfegh AJ, Friday JE, Goldman JP \& Chug Ahuja JK (1999) Presence of inulin and oligofructose in the diets of Americans. Journal of Nutrition 129, 7S, 1407S-1411S.

Prosky L (1999) Inulin and oligofructose are part of the dietary fiber complex. Journal of AOAC International 82, 223-226.

Roberfroid M (1997) Health benefits of non-digestible oligosaccharides. In Dietary Fiber in Health and Disease, pp. 211-219 [D Kritchevsky and C Bonfield, editors]. New York: Plenum Press.

Roberfroid M \& Delzenne N (1998) Dietary fructans. Annual Reviews of Nutrition 18, 117-143.

Van Loo J, Coussement P, De Leenheer L, Hoebregs H \& Smits $\mathrm{G}$ (1995) On the presence of inulin and oligofructose as natural ingredients in the Western diet. Critical Reviews in Food Science and Nutrition 35, 525-552.

Van Loo J, Cummings J, Delzenne N, Englyst H, Franck A, Hopkins M, Kok N, Macfarlane G, Newton D, Quigley M, Roberfroid M, van Vliet T \& van den Heuvel E (1999) Functional food properties of non-digestible oligosaccharides: a consensus report from the ENDO project (DGXII AIRIICT94-1095). British Journal of Nutrition 81, 121-132.

Walter T (1999) Bread goes prebiotic. International Food Ingredients 2, 20-21.

Wiedmann M, Jager M (1997) Synergistic sweeteners. Food Ingredients and Analysis International November-December, 51-56. 